\title{
Ontología crítica y lenguaje. Spinoza y la actualidad de un debate inconcluso sobre la ciencia y la filosofía *
}

\author{
Critical ontology and language. Spinoza and the actuality of an unfinished \\ debate on science and philosophy
}

\author{
Por: De Gainza, Mariana * \\ CONICET/ IIGG-UBA \\ Buenos Aires
}

Argentina

Email: marianagainza@gmail.com

Fecha de recepción: 6/04/2019

Fecha de aprobación: 25/05/2020

DOI: $\underline{10.30972 / n v t .1614348}$

\section{Resumen}

El racionalismo metafísico de la temprana modernidad, que concebía sus hipótesis sobre la base de una confianza en la unidad absoluta del ser, definía un horizonte de convergencia entre la filosofía y las ciencias. Sin embargo, ya se perfilaba el movimiento hacia la especialización, que produciría el panorama que hoy conocemos, marcado por la tendencia a la separación taxativa entre práctica científica positiva y reflexión filosófica. La perspectiva spinoziana, tal como Althusser la actualiza en los años 60, constituye una vertiente particular de la filosofía crítica que, introduciendo una tensión productiva entre imaginación y razón, vuelve a recordar la necesidad de que las disposiciones científicas y filosóficas se contaminen recíprocamente, para evitar su común empobrecimiento. A partir de Spinoza -

\footnotetext{
* Una primera versión de este trabajo fue presentada en el año 2016, en el II Coloquio UNAJ-CLACSO: Educación, Ciencia, Tecnología y Política, organizado por el Programa de Estudios de la Cultura (PEC) de la Universidad Nacional Arturo Jauretche (UNAJ).

* Es Licenciada en Sociología (UBA) y Doctora en Filosofía por la Universidad de San Pablo (USP), Brasil. Investigadora adjunta del CONICET y docente en el área de teoría política, en la carrera de Ciencia Política de la Facultad de Ciencias Sociales, UBA
} 
Ontología crítica y lenguaje.

Spinoza y la actualidad de un debate inconcluso sobre la ciencia y la filosofía

sostengo aquí- es posible concebir una ontología crítica, que considera al lenguaje como el territorio fundamental para una reconfiguración emancipatoria de lo real.

Palabras clave: Spinoza - Althusser - Ciencia - Ontología crítica - Lenguaje

\begin{abstract}
The metaphysical rationalism of early modernity, which conceived its hypotheses on the basis of a trust in the absolute unity of being, defined a horizon of convergence between philosophy and science. However, the movement towards specialization was already outlined, pointing to the situation of our days, marked by the tendency of total separation between positive scientific practice and philosophical reflection. The Spinozian perspective, as Althusser actualizes it in the 1960s, constitutes a line of critical philosophy that, introducing a productive tension between imagination and reason, recalls the need than scientific and philosophical dispositions contaminate each other, to avoid their impoverishment. From Spinoza -I assert hereit is possible to conceive a critical ontology, which considers language as the fundamental territory for an emancipatory reconfiguration of real.
\end{abstract}

Keywords: Spinoza - Althusser - Science - Critical ontology - Language

\title{
Cómo citar este artículo:
}

APA: De Gainza, M. (2020). Ontología crítica y lenguaje. Spinoza y la actualidad de un debate inconcluso sobre la ciencia y la filosofía. Nuevo Itinerario, 16 (1), 121-142. Recuperado de: (agregar dirección web)

I. Ciencia y filosofía. La normalidad positivista cuestionada

Suele recordarse que, en el siglo XVII, cuando las nociones de ciencia y filosofía ganaron su sentido propiamente moderno, ambas se articulaban en función de un mismo interés por la expansión de las fronteras del conocimiento. Así, el racionalismo metafísico de los albores de la modernidad, en todas sus versiones, compartía como 
rasgo que definía y enmarcaba su osadía especulativa cierta confianza en la unidad absoluta del ser, que fue descripta por Merleau-Ponty como "una manera inocente de pensar a partir del infinito" (Merleau-Ponty, 1964, p. 182). Se trataba de una vocación por desplegar un saber de lo "infinitamente infinito", esencialmente compatible con el naciente espíritu científico de la época. Pues aquella ciencia, que se entusiasmaba con las posibilidades de un análisis cada vez más exhaustivo de la naturaleza, trabajaba con el supuesto de que las fuerzas racionales propiamente humanas en nada se oponían al orden divino o a la perfección ontológica de la realidad.

Sin embargo, ya desde entonces se perfilaba el irresistible movimiento hacia la especialización, que acabaría por producir el panorama que hoy conocemos, marcado por una tendencia a la separación taxativa entre práctica científica positiva y reflexión filosófica. No obstante ello, aquella compenetración inicial entre ciencia y filosofía parece aún resonar, como añoranza y protesta, cada vez que se produce un paso adicional en el sentido del desencuentro que la historia fue confirmando. El pensamiento crítico vuelve a recordar periódicamente la necesidad de que las disposiciones científicas y filosóficas se contaminen recíprocamente, so pena de seguir reproduciendo una aquiescencia tácita con dos modos distintos de transitar la vía de su común empobrecimiento: el de una filosofía que se desentiende del problema de la verdad, y el de una ciencia indiferente a la autorreflexión sobre sus condiciones de producción y sobre lo inocuo de su lenguaje.

Pues bien, aquí voy a considerar una implicación peculiar entre ciencia y filosofía ensayada en los años '60 -de manera paralela, pero distante, a la del recién mencionado Merleau-Ponty-. Me refiero a los trabajos de Luis Althusser y su grupo, y en particular, a una iniciativa bastante ambiciosa en relación a este tema: el curso de filosofía para científicos, que tuvo lugar en la École Normale Supérieure de París entre 1967 y 1968 (Althusser, 1975). Lo que se buscaba entonces, una vez más, era restablecer los vínculos quebrados entre la producción de conocimientos y cierto tipo de reflexión, interna y externa a ella, que esa producción (lo sepa o no) ejercita y a la vez requiere. Existe de hecho -decía Althusser- una relación entre ciencia y filosofía, históricamente comprobable: las grandes revoluciones filosóficas han proseguido a las 
Ontología crítica y lenguaje.

Spinoza y la actualidad de un debate inconcluso sobre la ciencia y la filosofía

grandes revoluciones científicas, como su consecuencia, su efecto, su producto; de tal manera que es posible establecer una conexión inmanente entre la matemática griega y la filosofía de Platón, entre la física de Galileo y la filosofía cartesiana, entre la física newtoniana y la filosofía kantiana, o entre la lógica matemática y la filosofía de Husserl. La enumeración de esos grandes acontecimientos que sacudieron el campo del conocimiento, en realidad, apunta hacia la necesidad de pensar filosóficamente otros cismas de alta trascendencia: aquellos producidos por el materialismo histórico y por el psicoanálisis. Hay un llamado a la filosofía, entonces, para que se ponga a la altura de esos descubrimientos, los de Marx y los de Freud, que marcaron un antes y un después para los horizontes de la vida humana. Lo que está sugerido, en un debate implícito con las filosofías de moda en la época, es que ni el existencialismo, ni la fenomenología, ni el estructuralismo llegaron a formular conceptos adecuados para pensar en profundidad y proseguir las líneas trazadas por aquellas obras singulares, con una capacidad sin igual para destruir unos mundos y abrir otros.

Percibimos, entonces, que la noción de ciencia que se usaba en aquel contexto no era la habitual: no refería a la "ciencia normal" asociada con la práctica cotidiana de los científicos. Por el contrario, era algo que más bien debe ser considerado tan difícil como raro: aquello que efectivamente produce algo nuevo, y que, puesto que descubre un aspecto de la realidad hasta el momento desconocido, o mal conocido, trasforma esa realidad al producir su comprensión. Esa fuerza de transformación, propia del conocimiento en cuanto es conocimiento (y no en cuanto se aplica a una realidad que, entonces, se modificaría por esa aplicación), es radical en el caso de los grandes descubrimientos científicos, como el del inconsciente o la lucha de clases. Un gran descubrimiento constituye una ruptura y un comienzo: establece una separación frente a los modos espontáneos, naturalizados o ideológicos de conocer el mundo (un distanciamiento posibilitado por la comprensión de los efectos de desconocimiento que esos modos implican) y abre un nuevo territorio de investigación, es decir, de pensamiento, que inaugura una nueva forma de existencia y de temporalidad histórica, en virtud de la cual algo de la relación de los hombres con sus condiciones de existencia se modifica. 
Ahora bien, contra la tendencia a concebir tales "revoluciones científicas" en los términos habituales de un progresismo racionalista, se acentuaba un matiz clave. $\mathrm{Si}$ bien es cierto, por un lado, que las transformaciones producidas por descubrimientos como los de Freud o Marx tienen algo de irreversible; por otro lado, también es cierto que el hecho de que existan esos nuevos conocimientos (que interrumpen cierta forma de desconocer una realidad) nada garantiza. Ellos abren nuevas posibilidades para las luchas y las prácticas transformadoras, que pueden tanto ser proseguidas como resultar bloqueadas. Así, en cuanto una revolución teórica como la que produce el conocimiento sobre el inconsciente o la lucha de clases- abre la posibilidad de afirmar que“ tenemos una idea verdadera" ${ }^{1}$, esto sólo quiere decir que a partir de ese momento hay un suelo sobre el cual apoyarse para proseguir el trabajo crítico que produjo esa diferencia real. Pero si no persiste la actividad crítica, que enfrenta una y otra vez la opacidad, la no transparencia, lo enigmático de la experiencia (incluso la de quienes intentan proseguir las vías abiertas por una ciencia nueva) para producir en su interior la distinción entre lo que hay en ella de real y de imaginario, esa idea verdadera deja de generar efectos ${ }^{2}$.

En relación a esta manera peculiar de entender la ciencia, la inquietud no pasaría por preguntar, por ejemplo, si el psicoanálisis puede ser considerado o no una

\footnotetext{
${ }^{1}$ Se trata de una afirmación de Spinoza, en el Tratado de la reforma del entendimiento, que Althusser recuerda insistentemente. En relación con el "corte epistemológico" (el concepto bachelariano con el que los althusserianos pensaban los efectos de las revoluciones científicas) la encontramos mencionada en los "Elementos de autocrítica" (1972): “No me he atenido a una oposición 'no dialéctica' de la ciencia y la ideología: porque mostré que esta oposición era recurrente, por lo tanto, histórica y dialéctica, porque únicamente si el científico ha 'descubierto' y 'adquirido' la 'verdad' puede entonces, y tan sólo entonces, volverse, desde esta posición conquistada, hacia la prehistoria de la ciencia y calificarla, en todo o en parte, de error, de 'tejido de errores' (Bachelard) (...) Las verdades parciales y las anticipaciones de su prehistoria se reconocen e identifican ahí entonces como tales a partir de la verdad finalmente descubierta y detentada. 'Habemus enim ideam veram (Spinoza). En efecto, porque (enim) detentamos (habemus) una idea verdadera... podemos decir también 'verum index sui et falsi', lo verdadero se indica por sí mismo e indica lo falso; y también, por consiguiente, que el reconocimiento del error (como las verdades parciales) es la recurrencia de lo verdadero" (Althusser, 2008, pp. 185-186). 2 Balibar lo dice, acudiendo a una expresión hegeliana: “'La verdad no es una moneda acuñada, lista para ser gastada y atesorada', que se puede guardar en el bolsillo (prefacio de la Fenomenología del espíritu). Si no trabaja, desaparece" (Balibar, 2004, p. 18).
} 
Ontología crítica y lenguaje.

Spinoza y la actualidad de un debate inconcluso sobre la ciencia y la filosofía

ciencia $^{3}$, sino más bien por tratar de comprender qué es una ciencia después de que existe el psicoanálisis, es decir, cómo la idea de ciencia resulta modificada, alterada, transfigurada cuando algo tan importante como el descubrimiento del inconsciente por Freud ocurre de hecho, desacomodando todos los cánones con los que se pensaban los fenómenos psíquicos, tanto desde el sentido común como desde las ciencias existentes. Por eso, el ámbito de la filosofía de la ciencia se convertía en un territorio clave para pensar las implicancias permanentes de esas transformaciones, y elaborar una autorreflexión crítica sobre la práctica científica. Balibar lo expresa de la manera siguiente, involucrando en la misma pregunta tanto al psicoanálisis como al marxismo:

El problema general subyacente en la empresa de Althusser no es un problema propio de la filosofía francesa. Puede describírselo así: ¿qué clase de filosofía de la ciencia es susceptible de discutir, reconocer y experimentar [...] un modo revolucionario de saber científico concerniente a la sociedad, la práctica y el comportamiento humano? (Balibar, 2004, p. 9).

Y en cuanto esta inquietud sobre las condiciones de la producción de conocimientos también se plantea para las ciencias clásicas, la pregunta se especifica: “¿Cuáles son las posiciones ideológicas -por tanto, en último análisis, políticas- que se presentan en cualquier filosofía de la ciencia o epistemología, incluso cuando sólo se refieren a disciplinas 'tradicionales' y reconocidas, como la matemática o la biología?" (Balibar, 2004, p. 9).

La importancia asignada a este tipo de preguntas no se asocia con un imperialismo especulativo, que podría pretender que una elaboración puramente filosófica ocupe el lugar de la producción de conocimientos científicos. Se trata, más

\footnotetext{
${ }^{3}$ Recordemos que en estos términos se dio el famoso debate entre Gregorio Klimovsky y Mario Bunge. Cf. por ejemplo, M. Bunge, Pseudociencia e ideología, Madrid, Alianza, 1985; G. Klimovsky, Epistemología y psicoanálisis, Buenos Aires, Ediciones Biebel, 2004.
} 
bien, de entender que la producción de esos conocimientos tiene como condición interna una elaboración filosófica, o sea, una reflexión, un ejercicio de distinciones, de demarcaciones, que constituye una orientación en sentido amplio: un posicionamiento inmanente a la práctica en cuestión, que puede ser leído en sus implicaciones, interpretado y cuestionado. Así, para comprender muy esquemáticamente esta relación, puede decirse lo siguiente: el quehacer científico supone, efectivamente, que algo se hace (en el sentido de una producción o de un hacer relevante, y no de una actividad genérica), y adicionalmente, que algo se dice sobre lo que se hace, puesto que la ciencia siempre tiene una conciencia sobre su hacer. Entonces, la existencia de esta especie de metadiscurso científico indica que, de un modo u otro, lo que se hace está siendo pensado. Y sin embargo, la pregunta que se interpone aquí se relaciona con lo propiamente crítico de la indagación filosófica que incumbe a la ciencia: ¿eso está siendo verdaderamente pensado? ¿Hay allí realmente involucrada una actividad del pensamiento, o más bien deberíamos hablar de un pensamiento pasivo, de una pasividad del pensamiento? Esta es la manera en que la filosofía se vuelca sobre, o está siempre ya involucrada, en la actividad científica. Si el pensamiento se deja dominar por una inercia (por la repetición o la reproducción) piensa "mal", y lo mal pensado tiene consecuencias prácticas.

En función de esto, puede decirse que existen, a grandes rasgos, dos tipos de filosofías, que en aquel contexto se llamaban "idealistas" y "materialistas". Por un lado, aquellas que se orientan mayormente en el sentido de estabilizar, fijar y garantizar: que lo que hacemos está bien hecho, que lo que hacemos se corresponde con lo que somos (para el caso, "científicos"), que lo que la ciencia enfrenta es un objeto perfectamente reconocible, idéntico a sí mismo. Por otro lado, aquellas otras que desestabilizan, movilizan y cuestionan, permitiendo así establecer cierta distancia crítica respecto a lo que se hace, a lo que se es, y a la relación imaginaria que se sostiene con el objeto de conocimiento -una distancia que permite poner en duda, entonces, que ese objeto es tal cual lo vemos o tal cual lo pensamos-. Si esto es así, podemos comprender que el positivismo es la filosofía idealista que sintoniza de modo inmediato con la práctica científica, puesto que le permite establecer con claridad cuál 
Ontología crítica y lenguaje.

Spinoza y la actualidad de un debate inconcluso sobre la ciencia y la filosofía

es el sujeto de la actividad científica, con sus atributos o propiedades (espíritu analítico, neutralidad valorativa, etc.), así como delimitar el objeto de la indagación y pautar en detalle las normas que rigen su actividad: las reglas del método. Y, de esta manera, producir la distinción entre el conocimiento científico y el conocimiento no científico, que queda ubicado "más acá" de la ciencia: la opinión, la sensibilidad, la imaginación. Y eventualmente, señalar un "más allá" de la ciencia: la filosofía o la metafísica.

La filosofía crítica que no acepta esa trascendencia en relación a la producción de conocimientos es aquella que procura restituirle a la ciencia su capacidad de pensar -y "pensar", en este caso, significa también revisar la filosofía implícita que acompaña a esa ciencia, como si emanara directamente de ella-. Pensar, entonces, contra el automatismo reproductor que la conduce a sostener una relación con su práctica que se limita a reflejar los imperativos que surgen de ella, y que responden, a su vez, a imperativos sociales. El pensamiento que surge inmediatamente de la práctica científica como su pensamiento es, en ese sentido, imaginario o ideológico: expresa el modo en que se vive esa actividad, en conexión y en desajuste con el resto de las actividades de una sociedad; y no la inteligencia activa de esa actividad, como despliegue de un pensamiento que tiene por objeto, precisamente, aquel otro pensamiento que, en parte, responde a determinados imperativos sociales, políticos, históricos, ideológicos. El pensamiento crítico que despliega una perspectiva filosófica inmanente a cierta práctica científica es aquel capaz de repensar, discutir, reformular y hacerle preguntas no previstas a otro pensamiento que aparece como su objeto: aquel que está directamente imbricado con dicha actividad, porque surge espontáneamente de ella. El objeto del pensamiento crítico, entonces, no es "la realidad", sino el pensamiento que "responde directamente" a cierta actividad, esto es, que asume un conjunto de compromisos implícitos a ella. Ese "pensamiento espontáneo" cumple efectivamente un papel práctico: simplificar, facilitar, hacer fluir algo que debe funcionar; en virtud de lo cual, se comprende que colaborar en la reproducción de lo que actualmente funciona es un claro interés de la ideología positivista. 
De esta manera, si la actitud positivista supondría, como requisito para mantener la fluidez de la actividad científica cotidiana, cierta articulación entre un conocimiento y un desconocimiento: el desconocimiento de la ciencia respecto a la ideología de la que surge o que reproduce (una peculiar interpretación del imperativo de la neutralidad valorativa, diríamos); la respuesta crítica del althusserianismo spinoziano ante dicha posición dominante en el campo científico va a enfatizar, más bien, que esa ciencia que ignora la ideología que la sostiene no es una ciencia, sino una ideología. Una verdadera ciencia, por el contrario, sería más adecuada y paradójicamente definida como una "ciencia de la ideología". De manera que la ciencia que no expulsa a la reflexión filosófica fuera de su horizonte es aquella capaz de percibir el hecho de que toda ciencia es ciencia de la ideología de la que surge, es decir, comprensión de su propio surgimiento y de sus contextos de operación en sus necesarias articulaciones ideológicas o imaginarias. La ciencia que puede pensar las condiciones de su propia actividad puede, asimismo, considerar las ideologías que la constituyen y esforzarse por sostener una distancia en relación a ellas; lo que no implica la disolución o eliminación de esas ideologías, pues la relación imaginaria con la propia actividad es inmanente a esa misma actividad, y en tanto tal, insuprimible. Y es ese esfuerzo el que la hace ser, en cuanto ciencia que piensa, una ciencia crítica: una ciencia capaz de reconocer la necesidad histórica, social y política de ciertos modos dominantes y estereotipados de concebir el mundo; una ciencia capaz de conocer los mecanismos productores de puntuales desconocimientos e ilusiones, y capaz de saberse cautiva asimismo de esos mecanismos, pues sólo en la medida en que la fuerza de esos mecanismos es reconocida, es que se puede luchar contra ellos.

\section{Una ontología crítica}

Ahora bien, si recordamos lo que sugería al comienzo, esto es, que algo en el pensamiento filosófico de la temprana modernidad no aceptaba la compartimentación del mundo que luego consagraría la ciencia finalmente triunfante, podemos entender 
Ontología crítica y lenguaje.

Spinoza y la actualidad de un debate inconcluso sobre la ciencia y la filosofía

que la referencia althusseriana para concebir las relaciones entre ciencia e ideología haya sido, en gran medida, la filosofía de un pensador del siglo XVII, Spinoza. Y la diferencia en relación al comentario melancólico de Merleau-Ponty acerca de la inocencia -irremediablemente perdida- del racionalismo de aquellos tiempos idos radica en que Althusser reivindica la filosofía spinoziana por las potencialidades de su actualización contemporánea. En ese sentido, Spinoza no queda absorbido por la confluencia, enfatizada por Merlau-Ponty, de todo el pensamiento del siglo XVII en torno a un presupuesto ontológico común: el "infinito positivo". Pero resulta que si aceptamos la coincidencia de filósofos tan diferentes como Spinoza o Pascal, Leibniz o Bacon, Descartes o Locke, en torno a esa imagen común, eso tiene efectos muy concretos: asociamos esa noción de la infinitud con las ideas de convergencia, unidad, orden, armonía, acuerdo o mediación -entre exterior e interior, entre las cosas y el pensamiento, entre lo particular y lo universal-, donde el Dios infinito opera como la garantía última de la coherencia y la perfecta articulación de todos los componentes del mundo. La intención explícita de Merleau-Ponty, cuando produce esa homologación, es la de contrastar aquella manera ambiciosa de pensar la totalidad con la objetividad sin aura del "pequeño racionalismo" del siglo XX. Pero esa intención produce la consecuencia suplementaria de que el pensamiento del siglo XVII aparece, en bloque, como el antecedente y la base del positivismo moderno y contemporáneo: lo "pequeño" del nuevo racionalismo, en esta interpretación, surge del hecho de que procede circunscribiendo espacios al interior de esa infinitud positiva que sigue siendo, sin embargo, la fuente histórica de sus pretensiones de sistematicidad.

En cambio, Althusser insiste en la discontinuidad que hace de Spinoza un espécimen raro, que lleva adelante su vida filosófica en una peculiar relación de insubordinación frente a esa lógica clásica, responsable de la asociación del infinito con la pretensión de una "determinación completa" del ser, pautada por el imperativo de la armonía. Coincidiendo con esa manera de ver las cosas, podemos entonces afirmar, parafraseando a Marleu-Ponty, que el secreto del spinozismo consiste más bien en sostener un perpetuo movimiento de despositivización del infinito positivo. Es decir, el secreto de su manera singular de ser racionalista pasa por saber que el infinito actual 
sólo puede ser concebido a condición de ser despositivizado, o sea, a condición de que dejemos de imaginarlo, de manera inocente, como algo positivo. En esto consiste la deconstrucción de la totalidad o de la idea de Dios de la que parte la Ética de Spinoza, y que hace de su ontología una teoría crítica bastante peculiar ${ }^{4}$. Así, la conexión con la filosofía spinoziana (una ontología crítica concebida, a su vez, como una ética) es la que permite arrojar nueva luz sobre lo que sosteníamos, esto es, que las nociones de ciencia e ideología que defiende Althusser no tienen nada que ver ni con la ciencia normal, ni con la ideología como "concepción del mundo" o como "falta de objetividad", más o menos interesada.

Más de una vez se ha identificado a la perspectiva spinoziana con la filosofía en cuanto tal ${ }^{5}$. Esa asociación se funda, según creo, en la importancia estratégica del trabajo de la distinción en la filosofía de Spinoza. De manera que si pudo afirmarse que el spinozismo representaría lo que hay de igualmente filosófico en todas las filosofías (el trabajo efectivo del pensamiento en su esfuerzo de apropiación cognitiva de lo real), esta disposición es la que se encuentra realizada en su propia ontología, en sí misma identificable con la actividad del distinguir, esto es, con la práctica teórica de la

\footnotetext{
4 Para esta idea de "deconstrucción de la idea de Dios", reenvío a mi artículo "Perspectivismo y política" (Spinoza, Octavo Coloquio, 2012). "Puesto que no es una visión privilegiada desde la cual sea posible asignar nombres y distribuir sentidos, la perspectiva spinoziana se construye a la vez desde la afirmación de la pequeña verdad que una posición cualquiera aloja en sí ('tenemos una idea verdadera') y el agrietamiento sistemático del lugar virtual o terrenal que funge como fuente de emanación de las grandes verdades consagradas. Como tal fuente ha sido tradicionalmente Dios, el proceso de construcción de la perspectiva que nos presenta la Ética involucra el socavamiento progresivo de la identidad divina. 'Dios' no es igual a Dios, por dos motivos centrales que señalan una dirección externa y otra interior en las que trabaja la deconstrucción: 'Dios' no es igual a Dios, porque no es lo que habitualmente se entiende por Dios (es decir, no es la proyección de la figura humana del monarca rector de los destinos del universo, ni es una entidad espiritual, ni una noción moralizadora destinada a regular las conductas). Pero al mismo tiempo, 'Dios' no es igual a 'Dios' porque siempre es Dios 'en cuanto' (quatenus) afectado por otra cosa, por infinitas otras cosas. Un Dios que es eternamente otra cosa diferente de sí es otra cosa que Dios". Otra versión del mismo texto está disponible en: http://www.youkali.net/youkali15-b4-Gainza.pdf

5 Pueden recordarse, a modo de ejemplo, las palabras de Hegel: "Spinoza es tan fundamental para la filosofía moderna que bien puede decirse: quien no sea spinozista no tiene filosofía alguna" (G.W.F. Hegel, Lecciones sobre la historia de la filosofía, III. Trad. W. Roces, México, 1995, p. 305), o las de Bergson: "Todo filósofo tiene dos filosofías: la suya y la de Spinoza" (Carta de Bergson, leída por Paul Valéry, en la conmemoración del 250 aniversario de la muerte de Spinoza en la Sorbona, citada por Vidal Peña, El materialismo de Spinoza, Biblioteca de Filosofía no 5, Madrid, Revista de Occidente, 1974, disponible en: http://www.filosofia.org/aut/001/1974vp.htm).
} 
Ontología crítica y lenguaje.

Spinoza y la actualidad de un debate inconcluso sobre la ciencia y la filosofía

distinción (esto es lo que no sólo Althusser, sino también Deleuze ${ }^{6}$, han resaltado como característico de la ciencia spinoziana). El orden complejo de su ontología, elaborada como conexión de distinciones es, así, el resultado de un esfuerzo de comprensión de las diferencias reales que hacen a la diversidad del mundo, que exige asimismo la deconstrucción de las demarcaciones imaginarias que organizan la experiencia común. La potencia específica de esta actividad de separación efectuada por el pensamiento encuentra su fundamento en una posición que no pretende huir de esa experiencia común imaginariamente organizada, sino interrogarla; elaborando, en el proceso de esa interrogación, una lógica de lo real que, como causalidad inmanente que afirma la necesidad de la determinación, permite asimismo una indagación ética sobre las condiciones materiales (afectivas y sociales, subjetivas y objetivas) de la libertad como una alternativa difícil y rara, pero existente en tanto posibilidad real para las sociedades humanas. Se trata, entonces, de una Ética, que en cuanto pretende ser "demostrada geométricamente", involucra desde su propia concepción aquella imbricación entre filosofía y ciencia a la que nos referimos.

En ese contexto, la distinción spinoziana no es sólo el operador fundamental de la diferenciación ontológica de los seres y de la constitución también diferenciada de las ideas, sino que tiene un papel clave en el desarrollo de la crítica filosófica. Si para Spinoza una mente individual puede identificarse con su propia fuerza interna para ordenar imágenes e ideas (de tal manera que esa conexión coincida con el orden de la determinación real de las cosas) sólo cuando logra distinguirse de lo que la determina externamente a pensar ciertas cosas y no otras (según un orden fortuito de encuentros y acontecimientos), un pensamiento crítico $-\mathrm{y}$ éste es el énfasis althusserianotambién se constituye distinguiéndose. Para comprender la noción de ciencia de Althusser, entonces, hay que tener en cuenta esta dinámica spinoziana de la producción de ideas adecuadas. La ciencia (como crítica de la ideología) se produce como un movimiento de diferenciación: respecto a una tradición en referencia a la cual se forma en una primera instancia; respecto al conjunto de las interlocuciones que explican la conformación de ese pensamiento; respecto al pensar sintonizado con las

\footnotetext{
${ }^{6}$ En relación a esto, remito a Gainza, 2018.
} 
formas dominantes de la producción de ideas en una sociedad determinada. Y de confrontación, también, respecto a los diversos adversarios teóricos, que muchas veces son defensores de los sentidos instituidos que el cuerpo teórico extraño viene a sacudir. Es por eso que, según esta noción de ciencia, una innovación teórica profunda puede sustentarse en una simple actividad de distinción, que transfigura el campo de las identificaciones con las que se constituyen tanto el sentido común como los pensamientos oficiales o consagrados.

Digamos esto mismo con un ejemplo spinoziano, a través de la manera en que Althusser lo rememora. En la Ética, leemos:

Cuando contemplamos el Sol, imaginamos que dista de nosotros aproximadamente doscientos pies, en lo que nos equivocamos mientras ignoramos su verdadera distancia; ahora bien, conocida esa distancia, desaparece el error, ciertamente, pero no aquella imaginación, es decir, la idea del Sol que explicita su naturaleza sólo en la medida en que el cuerpo es afectado por él, y de esta suerte, aunque conozcamos su verdadera distancia, no por ello dejaremos de imaginar que está cerca de nosotros", $E$, IV, P I, escolio (Spinoza, 1983, p. 251).

Tomándose de esto, entonces, Althusser escribe en una carta dirigida a Paul Ricoeur (que cito in extenso):

[Existe] un malentendido sobre la función efectiva del conocimiento científico. Veo el principio de ese malentendido en una actitud contemplativa, que 'espera' de la ciencia una especie de reproducción, de re-animación, de re-presentación, o más bien de representificación de lo real mismo en su inmediatez (...) No se puede dejar de pensar en aquellos cartesianos terriblemente confundidos por aquel regalo que les hacían los astrónomos: un segundo sol. ¿Cómo conciliar el sol del campesino con el sol del astrónomo? Había un sol de sobra. El de la ciencia. Y manifiestamente incapaz de expulsar la imagen del otro, de 'hacerle aparecer' de un modo que no sea 'a 
Ontología crítica y lenguaje.

Spinoza y la actualidad de un debate inconcluso sobre la ciencia y la filosofía

doscientos pies'. ¡Qué problema! No había suficiente Dios para sacarles de ese aprieto. En realidad, sólo había un sol de sobra para los nostálgicos de la percepción, para los que tenían miedo, creyendo en el otro, de perder su sol a doscientos pasos, y que esperaban que el astrónomo les recreara el sol mismo; para los que no veían, si se me permite decirlo, que el segundo sol no reemplazaba ni suprimía al primero, sino que, por más lejos que estuviera, en otro plano permitía la inteligencia del sol inmediato, y la acción sobre sus efectos (Althusser, 2008, pp. 31-32).

Entonces, por el hecho de que Spinoza se diferencia de sus propios interlocutores y de una tradición en el contexto de la cual se forma (la de aquellos cartesianos "terriblemente confundidos" por no poder compatibilizar los sentidos comunes que respaldan sus posiciones filosóficas con ciertos descubrimientos científicos), puede indicar que somos capaces de saber que, aunque lo veamos a doscientos pies, el sol no está allí; registrando a la vez el hecho de que, si así lo vemos, es por una asociación necesaria entre ciertas propiedades del sol y nuestra propia constitución corporal. Y dado que, en el contexto de una ética, estas cuestiones valen para reflexionar acerca de la falsa idea que los hombres se hacen acerca de su libertad ${ }^{7}$, se entiende asimismo que el ejemplo spinoziano sea esgrimido por Althusser para pensar "científicamente" la historia, contra el empirismo dominante entre los historiadores:

\footnotetext{
${ }^{7}$ Cosa que vemos, claramente, si nos remitimos a la primera aparición del ejemplo del sol en la Ética: "los hombres se equivocan al creerse libres, opinión que obedece al solo hecho de que son conscientes de sus acciones e ignorantes de las causas que las determinan. Y, por tanto, su idea de 'libertad' se reduce al desconocimiento de las causas de sus acciones, pues todo eso que dicen de que las acciones humanas dependen de la voluntad son palabras, sin idea alguna que les corresponda. Efectivamente, todos ignoran lo que es la voluntad y cómo mueve el cuerpo, y quienes se jactan de otra cosa e inventan residencias y moradas del alma suelen mover a risa o a asco. Así también, cuando miramos el Sol, imaginamos que dista de nosotros unos doscientos pies, error que no consiste en esa imaginación en cuanto tal, sino en el hecho de que, al par que lo imaginamos así, ignoramos su verdadera distancia y la causa de esa imaginación. Pues, aunque sepamos más tarde que dista de nosotros más de 600 diámetros terrestres, no por ello dejaremos de imaginar que está cerca; en efecto, no imaginamos que el Sol esté tan cerca porque ignoremos su verdadera distancia, sino porque la esencia del Sol, en cuanto que éste afecta a nuestro cuerpo, está implícita en una afección de ese cuerpo nuestro" (Etica, II, P 35, escolio).
} 
Del mismo modo que el conocimiento de las leyes de la luz no ha impedido nunca que los hombres vean incluso el sol a doscientos pies, ni ha reemplazado ni amenazado su simple mirada, tampoco el conocimiento de las leyes que dirigen el desarrollo de las sociedades impide que los hombres vivan, ni sustituye al trabajo, al amor y a la lucha. Por el contrario: el conocimiento de las leyes de la luz ha producido las gafas, que han transformado la mirada de los hombres, del mismo modo que el conocimiento de las leyes del desarrollo de las sociedades ha producido empresas, que han transformado y ampliado el horizonte de la existencia humana (Althusser, 2008, p. 33).

III. Problemas de lenguaje

El empirismo es, entonces, una de las posiciones adversarias que esta noción de una ciencia que busca la inteligencia activa de las cosas del mundo confronta. El positivismo científico se presenta como empirismo, cuando la ciencia se concentra en eso que aparece frente a ella como lo dado, los hechos (un objeto que, según se supone, contiene en sí mismo "la verdad"), y se comporta ante esa realidad como si el conocimiento científico no fuera más que el registro, la lectura, la contabilidad (cuasi notarial) del contenido de ese objeto:

Mirar bien, observar bien, ver bien, leer bien, constatar bien, registrar bien, contabilizar bien, con las palabras convenientes: he aquí todo el conocimiento científico. Todo lo que puede hacer la ciencia es respetar las reglas de esta pasividad y registrar bien en una buena contabilidad los resultados de su lectura. En el límite, el empirista dice: 'La ciencia es una lengua bien hecha'. Lengua bien hecha: para escribir libros de cuentas exactas y exhaustivas (Althusser, 1995, p. 275).

Se comprende, entonces, que para esta manera de entender la ciencia, las reglas del método sean lo principal, pues lo que básicamente se busca es que sea bien aplicada la técnica abstractiva (una serie estipulada de procedimientos) requerida para destilar la 
Ontología crítica y lenguaje.

Spinoza y la actualidad de un debate inconcluso sobre la ciencia y la filosofía

verdad que habitaría en las cosas. En virtud de esa función de revelación que se le atribuye, el método tiende a ocupar el lugar de la teoría, que se ausenta. Y por ese conjunto de desplazamientos (la adjudicación de la verdad al objeto, la reducción de la teoría a una metodología, la identificación de ese método con una técnica o procedimiento), lo que se pierde es, precisamente, el pensamiento, que pasa a ser la crónica de una secuencia de hallazgos rutinarios. O dicho con otras palabras: se pierde el sujeto, se pierde la perspectiva crítica, se pierde la posibilidad una mirada renovada sobre el mundo.

Suele oponérsele, a esta actitud de la ciencia, otra que se pretende contraria a ella, y que reivindica, frente al absolutismo objetivista, el lado "subjetivista" -que sin embargo no presenta más que la misma comprensión de la ciencia, desde su otro polo-. El formalismo, dominante en buena parte de las disciplinas científicas, reifica el signo, que pasa a substituir al objeto. En este caso, el método ya no es una técnica de lectura y de abstracción (entendida como extracción), sino una técnica de escritura algorítmica, de formalización, de programación y de cálculo (en la cual aún hoy podríamos seguir reconociendo el horizonte utópico de la característica universal de Leibniz):

Aquí todavía el trabajo de la ciencia se reduce a establecer una 'lengua bien hecha', no en el sentido de una contabilidad o inscripción de lo dado en un vocabulario existente en una lengua natural, sino en el sentido de la escritura, del trazo de algoritmos, permitiendo enseguida al cálculo operar solo sobre ellos. (...) La ciencia recoge los resultados del cálculo automático. En lenguaje moderno, programa una máquina y recoge los resultados de sus cálculos (...) Toda la ciencia moderna de vanguardia está actualmente dominada por esta tendencia formalista (Althusser, 1995, pp. 279-280).

Ahora bien, lo que subyace a esta idea de una "lengua bien hecha" es el imperativo de la adecuación armoniosa entre el pensamiento y la realidad, a través del medio neutral del lenguaje de la ciencia o la metafísica. Y en esta noción práctica clave se reconocen, 
asimismo, los ecos de aquel proyecto de una comprensión a la vez infinita y acabada del universo por parte del racionalismo del siglo XVII.

Sin embargo, he sugerido que Spinoza -de manera discordante en relación a algunos de sus célebres contemporáneos, como Descartes o Leibniz- puede ser reivindicado como un pensador de la "despositivización" del ser, con consecuencias relevantes en lo que refiere al modo de concebir la ciencia. Lo que quisiera ahora remarcar es que la actividad de distinción en la que consiste la filosofía crítica spinoziana pasa, necesariamente, por un trabajo minucioso y concienzudo que tiene como su elemento al lenguaje. Para que la noción de "Dios" (así como el resto de los términos movilizados en la escritura de la Ética) se asocie con un sentido completamente diferente al sentido tradicional (pues en eso consiste, según sugerí, la deconstrucción de la totalidad tal como la lleva adelante Spinoza), es preciso que esa disociación, ese quiebre de las significaciones, sea incorporada al concepto mismo, que entonces, agrietándose desde dentro, se constituye como concepto complejo y crítico. Como bien lo entendió Pierre Bayle, filósofo francés del siglo XVII, Spinoza "atribuye a las palabras una significación totalmente nueva, sin advertir a sus lectores"; de manera que los términos clave de su filosofía, "en vez de tener el sentido que deben tener" son usados en un sentido "desconocido para los filósofos" (Bayle, 1983, p. 26). Esa actividad de corrosión de ciertas nociones filosóficamente hegemónicas se produce, en la ontología spinoziana, gracias al trabajo definicional, que va operando en los términos tradicionales desvíos sutiles y acumulativos. Un uso desviante de los nombres consagrados del cual Spinoza -cabe resaltar- es perfectamente consciente, pues así lo reconoce en un comentario al pasar que hace en la Ética: "Sé que estos nombres significan otra cosa en el uso corriente. Pero mi designio no es el de explicar la significación de las palabras, sino la naturaleza de las cosas, designando éstas con aquellos vocablos cuya significación según el uso no se aparte enteramente de la significación que yo quiero atribuirles" ( $E$ III, Definición de los afectos, XX, explic.). La habilidad para inscribir, en el interior mismo de las palabras, esa distancia (la diferencia entre su significación corriente y el nuevo sentido que se les quiere atribuir) constituye un modo a la vez sensible y estratégico de lidiar con la materia indócil del 
Ontología crítica y lenguaje.

Spinoza y la actualidad de un debate inconcluso sobre la ciencia y la filosofía

lenguaje, que sólo puede ser desplegado por un pensamiento que verdaderamente busca la comprensión de las cosas reales.

Y, a la vez, esa tentativa de explicar la naturaleza de las cosas no puede dejar de tener en cuenta las dificultades que dicho trabajo con las palabras presenta en general. Pues las palabras forman parte de la imaginación -sostiene Spinoza- y son inseparables de las disposiciones variables del cuerpo y de las conexiones que establece la memoria para organizar una experiencia que, de otro modo, sería fragmentaria y caótica ${ }^{8}$. Se trata, entonces, de quebrar la estructura asociativa que instituye un lenguaje espontáneamente organizado según finalidades prácticas y de darle cauce, con palabras y en contra de las palabras (con imágenes y en contra de las imágenes), a la actividad del pensamiento, que elabora esa experiencia imaginaria siempre y necesariamente atravesada por el lenguaje.

Ahora bien, cuando el pensamiento intenta comprender realidades que no son imaginables, debe precaverse en relación a esa vinculación originaria de las palabras, que, como la imaginación, pueden ser causa de todo tipo de errores. Y llego, aquí, a un punto que quisiera resaltar, porque mantiene con el tema de la crítica al positivismo al cual me referí a lo largo de este texto- una relación tan estrecha como la que conecta, precisamente, el problema del pensamiento con el problema del lenguaje.

Para referirse a la necesaria distinción que siempre hay que esforzarse en hacer entre las palabras y las cosas, Spinoza alude a lo positivo y a lo negativo, de una manera que, según creo, arroja una nueva luz sobre lo inapropiado de atribuirle, a él, una concepción de la infinitud identificable con la de sus contemporáneos. El mejor ejemplo que Spinoza encuentra para alertar sobre los problemas relativos al lenguaje es, justamente, la confusión corriente entre la naturaleza de lo infinito y la de lo finito, debida a la generalizada disposición a concebir la realidad de lo que es infinito a partir de la perspectiva de lo finito que, mediante la proyección de la situación que le es

\footnotetext{
8 "Dado que las palabras forman parte de la imaginación, es decir, que, como formamos muchos conceptos conforme al orden vago con que las palabras se asocian en la memoria a partir de cierta disposición del cuerpo, no cabe la menor duda de que también las palabras, lo mismo que la imaginación, pueden ser causa de muchos y grandes errores, si no los evitamos con esmero" (Spinoza, 1988, p. 113)
} 
propia, trata de remontarse más allá de su horizonte de conocimiento próximo. Así, si por un lado la experiencia inmediata viabiliza el surgimiento de ciertas ideas que, por estar asociadas a imágenes -producidas a partir de roces reales, resultantes de una causalidad física operante- son "positivas" (ideas que, como dice Spinoza, se presentaron primeramente a los hombres y acapararon los términos afirmativos) ${ }^{9}$, por otro lado, aquello que no es susceptible de ser imaginado y que sólo puede ser entendido fue generalmente concebido como lo contrario de esa positividad originaria $y$, por ello, ha sido expresado con nombres negativos. La experiencia de lo que es corpóreo, finito, creado, dependiente o mortal sirve entonces de base -paradójica e insuficiente- para construir las nociones de incorpóreo, infinito, increado, independiente o inmortal. Paradójica, pues esa base sólo sustenta el sentido perseguido en tanto es negada, de modo tal que nuestra reconstrucción espontánea de la noción de independencia o infinitud se asienta en la idea que tenemos de lo que no es dependiente o de lo que no es finito (tal como lo experimentamos). Insuficiente, pues para revelar que una cosa es infinita y para caracterizar esa propiedad suya no alcanza con decir que esa cosa es no-finita; ni tampoco agregando determinaciones negativas, diciendo que lo infinito es ilimitado, inconmensurable, inmenso, increado, interminable o imperecedero (pues sólo se afirmaría, de esa forma, que lo infinito es impensable).

Entonces, lo positivo y lo negativo reenvían, en gran medida, a cierta arbitrariedad asociada al uso de las palabras. Pero además, hay un buen motivo para prestar especial atención a lo referido mediante términos negativos, más que a lo positivamente denotado. Pues, si como dice Spinoza, los términos afirmativos se asociaron originariamente a la experiencia inmediata y, por eso, a la imaginación, aquellas otras cosas que no pueden imaginarse, sino que solamente pueden ser concebidas gracias a la acción intelectual (como el infinito), recibieron muchas veces nombres negativos. Por eso, vale la pena resaltar: esos términos pueden ser valorados como índice de referencia de alguna cosa difícil de ser pensada por un pensamiento inmediato y, por lo tanto, como señal que nos orienta en relación a la necesidad de

\footnotetext{
${ }^{9}$ Cf. Tratado de la reforma del entendimiento, $\S 89$ (Spinoza, 1988, p. 113).
} 
Ontología crítica y lenguaje.

Spinoza y la actualidad de un debate inconcluso sobre la ciencia y la filosofía

realizar un esfuerzo conceptual adicional. Un esfuerzo que no debe reducirse, no obstante, a proseguir acríticamente por el camino que las palabras nos sugieren. Un nombre -como infinito- señala algo que exige ser pensado, pero no lo expresa. Es decir, la realidad ideal que la palabra diseña en virtud de una lógica interna al lenguaje no se corresponde con la realidad de la referencia. Por eso, aunque "in-finito" nos sugiera lo contrario de "finito" (lo que niega lo finito), debe evitarse -contra la palabra- esa seducción por el sentido inmediato, para que pueda ser construida -con otras palabras- la idea compleja que la realidad de la cosa demanda como su idea. Otras palabras para el infinito: necesidad de la existencia, necesidad de la existencia de infinitas cosas en infinitos modos, que solicitan y admiten una explicación distinta que las comprenda en sus diferencias irreductibles.

Esa objetividad (las modulaciones finitas de esa existencia necesaria) reclama entonces un sujeto capaz de dar cause al trabajo de la distinción. Ese sujeto coincide con cierta posición ética de la ciencia, que podemos caracterizar como aquella que ya no requiere postular un más acá de sus fronteras, que la inmuniza frente a la sensibilidad y la imaginación, y un más allá, que la separa de la filosofía. Si caracterizamos esa posición con Spinoza, podemos entenderla como la expresión determinada de una potencia de pensamiento, que no puede dejar de ser expresiva de las determinaciones (externas) que la constituyen. Pero que, a su vez, es capaz de sostener ese tipo específico de relación con la verdad que define al conocimiento, en cuanto es capaz de volverse reflexivamente sobre esa determinación: no sólo reflejarla, sino también formarse como su idea, es decir, como potencia de concebirla. Esto implica, en una torsión simultánea, que el propio pensamiento se conciba a sí mismo (o sea, se constituya como idea de una idea verdadera): al mismo tiempo como producto de esa determinación, y como capaz de producir un conocimiento de su propia situación, que es la base crítica de la producción de cualquier verdad: sabernos como el saber de lo que nos determina. Una perspectiva expresiva puede ser verdadera, de esta forma, si es capaz de afirmarse como sensibilidad (que para Spinoza, básicamente, consiste en la escucha apropiada de las orientaciones que la corporeidad ofrece -pues "yerran o se equivocan las almas, no los cuerpos", E II, P 35 - 
Spinoza, 1983, p. 140) y como crítica (capaz de negar activamente, a través del pensamiento, lo que favorece las condiciones que actúan en favor de la impotencia), y desplegar los efectos de conocimiento que se siguen de esa posición. Puede ser verdadera, decimos, pues una perspectiva expresiva de las determinaciones que la constituyen también puede ser falsa (representar un conocimiento confuso o mutilado), si es meramente reproductiva del condicionamiento externo, que se limita a reflejar, sin sobre él reflexionar.

\section{Bibliografía:}

Althusser, L. (1975). Curso de filosofía para científicos. Barcelona: Laia.

Althusser, L. (1995). "Du côté de la philosophie". En Écrits philosophiques et politiques, T. II. París: Stock/Imec.

Althusser, L. (2008). "Elementos de autocrítica”. En La soledad de Maquiavelo. Madrid: Akal.

Althusser, L. (2008). "Sobre la objetividad de la historia. Carta a Paul Ricoeur". En La soledad de Maquiavelo. Madrid: Akal.

Balibar, E. (2004). “El concepto de 'corte epistemológico' de Gastón Bachelard a Louis Althusser". En Escritos por Althusser, Buenos Aires: Nueva Visión.

Bayle, P. (1983). "Dictionnaire historique et critique, Article Spinoza". En Écrits sur Spinoza. París: Berg International Éditeurs.

Gainza, M. (2013). "Spinoza: historia y política en perspectiva”. En Youkali: revista crítica de las artes y el pensamiento n. 15, Madrid, pp. 133-138. Disponible en: http://www.youkali.net/youkali15-b4-Gainza.pdf

Gainza, M. (2018). "El problema de las distinciones en Spinoza. Una subversión crítica de Descartes". En Endoxa n. 41 Universidad Nacional de Educación a Distancia, Facultad de Filosofía, Madrid. Disponible en: http://revistas.uned.es/index.php/endoxa/article/view/19387 
Ontología crítica y lenguaje.

Spinoza y la actualidad de un debate inconcluso sobre la ciencia y la filosofía

Merleau-Ponty, M. (1964). "Por doquier y en parte alguna”. En Signos, Barcelona: Seix Barral.

Spinoza, B. (1983). Ética demostrada según el orden geométrico. Trad. de Vidal Peña. Buenos Aires: Ediciones Orbis.

Spinoza, B. (1988). "Tratado de la reforma del entendimiento". En Tratado de la reforma del entendimiento / Principios de Filosofía de Descartes / Pensamientos Metafísicos. Trad. de Atilano Domínguez. Madrid: Alianza 